\title{
The importance of anemia and health-related quality of life in the elderly
}

\author{
Raditya Wratsangka*@ and Rully Ayu Nirmalasari Haryadi Putri**
}

\section{ABSTRACT}

Anemia is a global health problem with an extremely high prevalence and occurring in nearly $25 \%$ of the world population, particularly in the elderly group. Currently Indonesia is facing a rapid growth of the elderly population, with around 21 million elderly ( $8.2 \%$ of the total population), that is projected to increase to 33.7 million $(11.8 \%)$ in the year 2025 . Anemia in the elderly is frequently neglected, although the facts show that low hemoglobin concentration is an important marker of physiological decline and functional limitations. Although the factor of intrinsic aging may cause low hemoglobin concentration, anemia in the elderly is known to have a wide range with regard to etiology, underlying disorders, and possible mechanisms, such that it should be clinically followed up. Whatever its causes or underlying pathophysiological, anemia in the elderly has been proven to play a role in their morbidity and mortality, and may decrease their quality of life, that comprises all aspects of physical, mental, and social health, known as health-related quality of life (HRQoL). The impact of anemia on HRQoL has been studied in various populations, and most studies report the presence of an association between HRQoL and anemia in elderly individuals, which on the subscale level is particularly associated with physical health. Early diagnosis of anemia is important to prevent aggravation of the condition, to retard the progress of the disease, and to improve the health-related quality of life (HRQoL) of the patient. Prior to determining the treatment plan, the primary diagnosis and the comorbidities, especially treatable disorders, had better be identified first. The available data show that the overall prognosis will improve for anemia in patients with well-managed and corrected chronic disorders.

Keywords: Anemia, elderly, health-related quality of life
@Department of Obstetrics and Gynecology, Faculty of Medicine, Trisakti University

\section{Correspondence:}

Dr.dr. Raditya Wratsangka, Sp.OG(K) Department of Obstetrics and

Gynecology,

Faculty of Medicine,

Trisakti University

Email: raditya@trisakti.ac.id

ORCID ID: 0000-0001-6524-8336

Date of first submission, February 3, 2020

Date of final revised submission, July 18,2020

Date of acceptance, July 21, 2020

This open access article is distributed under a Creative Commons AttributionNon Commercial-Share Alike 4.0 International License

Cite this article as: Wratsangka R, Putri RAH. The importance of anemia and health-related quality of life in the elderly. Univ Med 2020;39:135-49. doi: 10.18051/UnivMed.2020.v39.135149 


\section{INTRODUCTION}

Anemia is a condition in which the number and size of the red blood cells or the hemoglobin concentration are below the normal value, such that it reduces the capacity of the blood to transport oxygen to the whole body, and there is insufficient oxygen for satisfying the physiological needs, the size of which varies and is affected by age, gender, behavior/activity, smoking habit and pregnancy status. According to the criteria established by the World Health Organization (WHO), anemia is defined as a hemoglobin concentration of $<13.0 \mathrm{~g} / \mathrm{dL}(8.0$ $\mathrm{mmol} / \mathrm{L})$ in adult males and $<12.0 / \mathrm{dl}(7.5 \mathrm{mmol} /$ L) in non-pregnant adult females. ${ }^{(1,2)}$ Anemia is a global health problem that is experienced by people in developing as well as developed countries and has a detrimental impact on health, economic and social problems. ${ }^{(3)}$ The prevalence of anemia is very high and this disease is found in almost $25 \%$ of the world population. ${ }^{(4)}$ The elderly are an important part of the demographic population, with an extremely rapid growth in numbers, which is also in line with the increased prevalence of anemia that is associated with the age of an individual. ${ }^{(5)}$ In developing countries, anemia is a condition that is most frequently experienced by elderly individuals, with an estimated prevalence of around $10 \%$ of individuals aged 65 years and older. ${ }^{(3,6)}$

Life expectancy and various causes of death have long been used as indicators of the health of a population or community. Although these indicators provide critical information on the health status of a population, they do not do the same on the quality of the physical, mental and social aspects of life. When quality of life is associated with the problem of health and/or disease, there is the term quality of life in connection with health or health-related quality of life (HRQoL), to differentiate it from other aspects of quality of life. The progressive increase in life expectancy also contributes to the increased prevalence of chronic diseases in the elderly population.
At present Indonesia is facing a rapid growth of the elderly population, ${ }^{(7)}$ such that Indonesia is home to the eighth largest elderly population in the world and the fourth among the Asian countries. With an elderly population of around 21 million (8.2\%), Indonesia has become the country with the largest number of elderly in Southeast Asia. From the results of a population census conducted in 2010, it was found that the number of persons aged 60 years and older was 18.1 million or $7.6 \%$ of the total Indonesian population. This number is projected to increase to 33.7 million (11.8\%) in the year 2025, and will approach 48.2 million (15.8\%) in 2035. ${ }^{(8)}$ In certain population groups, anemia has been reported to be associated with impaired body defenses and reduced HRQoL. The impact of anemia on HRQoL has been investigated in patients from differing populations, including patients with chronic kidney disease, chronic obstructive pulmonary disease, cancer, cardiac disorders, and others. ${ }^{(4)}$ The objective in writing this article was to provide better insights into the causes of anemia and their impacts on HRQoL in the community-dwelling population, especially the elderly who may participate in various interventions on the prevalence of anemia.

\section{Epidemiology of anemia in the elderly population}

Anemia is experienced by around onefourth of the world's population, especially by pregnant women, adolescents, and the elderly. (4) The extremely varying prevalence of anemia in the elderly in a number of different populations is caused by the heterogeneity of the populations under study, and also by adjustment of the results to ethnicity, health status and research design. ${ }^{9-}$ 11) The Third National Health and Nutrition Examination Survey (NHANES III) has fulfilled a number of these characteristics and provided very comprehensive basic data that allowed to obtain specific prevalence rates of anemia regarding age and gender in the total US population and was adequate for determining the 
causes of anemia in the population aged 65 years or older. ${ }^{(10,12,13)}$

Based on the criteria or definition of anemia established by the World Health Organization (WHO), i.e. a hemoglobin concentration of $<13.0 \mathrm{~g} / \mathrm{dL}(8.0 \mathrm{mmol} / \mathrm{L})$ in adult males and $<12.0 / \mathrm{dl}(7.5 \mathrm{mmol} / \mathrm{L})$ in non-pregnant adult women, more than $10 \%$ of persons aged 65 years or older have anemia. ${ }^{(14)} \mathrm{A}$ prospective study with a large sample size has revealed prevalence rates of anemia in $10-24 \%$ of elderly individuals. A large-scale epidemiological study reported an incidence of anemia of around 6$12 \%$ in community-dwelling elderly. Hospitalized elderly adults frequently have anemia (40\%) and a higher prevalence was found $(47 \%)$ in those in nursing homes. ${ }^{(15)}$ In the United States, around $10.2 \%$ of females aged 65 years or older have anemia, and this prevalence ate increases with advancing age, and subsequently the frequency of anemia increases two-fold at age 85 years and older as compared with the age group of $65-84$ years. ${ }^{(16)}$ The prevalence of anemia in German community-dwelling elderly individuals reached more than $20 \%$ and in hospitalized geriatric patients the incidence rate increased to more than $40 \%{ }^{(17,18)}$ In Brazil, the prevalence of anemia was $18.6 \%$, with a prevalence in females and males of $17.6 \%$ and
$20.8 \%$, respectively. ${ }^{(19)}$ The results of a crosssectional study conducted in Mampang Prapatan District, South Jakarta, Indonesia, showed that the incidence rate reached $26.2 \%$ in the elderly, with a higher prevalence in females than in males. ${ }^{(20)}$ Data reported by the China National Nutritional Health Survey (CNNHS) showed that the prevalence of anemia in females aged 60 years or older who resided in rural areas was almost 1.5-fold that of those residing in urban areas, for the same age group. Currently, with the rapid economic growth, several changes have occurred in dietary pattern and life style in China, especially in urban areas. With the increased living standards, the incidence rate of malnutrition in the elderly has decreased significantly. ${ }^{(18)}$ The epidemiology of anemia and the elderly in general are a common challenge for all of us, because of the increased heterogeneity as regards the distribution of these risk factors in connection with the increased social and biologic risks associated with the advancing age of an individual. A national community-based cross-sectional study on the Polish population involving respondents aged 65 years or older, reported a prevalence of anemia that increased with advancing age, and reached more than $50 \%$ in males and females aged over 80 years in the Polish population (Figure 1). ${ }^{(21)}$

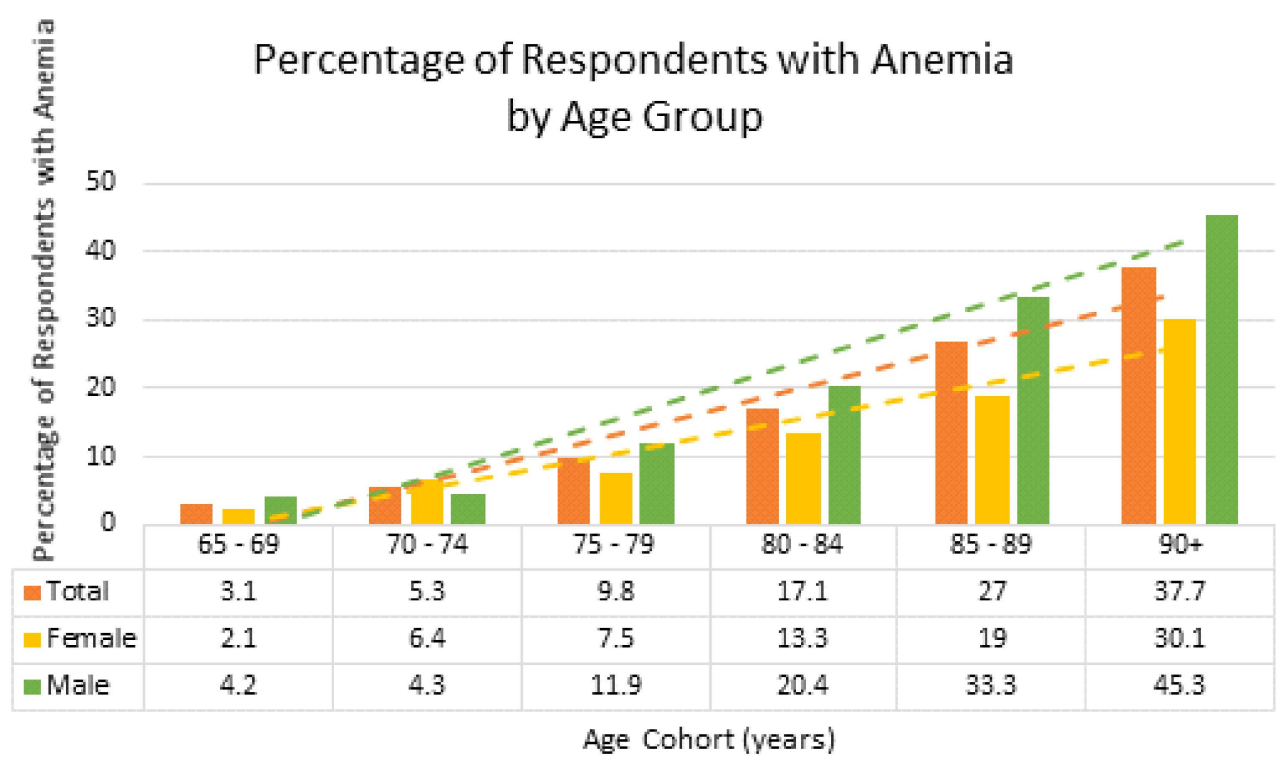

Figure 1. Increased prevalence of anemia in the elderly ${ }^{(21)}$ 


\section{Causes of anemia in the elderly}

The majority of elderly with anemia have identifiable pathological causes. Although intrinsic aging may also cause lowered hemoglobin concentrations, it is best not to consider this as the main cause of anemia, including in the oldest elderly, because there may also be several causes in the same patient. Anemia in the elderly is known to have a wide range of causes, several underlying disorders, and their possible mechanisms. ${ }^{(13,15,22)}$ The National Health and Nutrition Examination Survey (NHANES) is a wide community-based survey with samples representing community-dwelling groups of elderly in the United States. Its study results suggest a classification of anemia into four main categories, namely nutritional deficiency anemia (iron, folate and vitamin B12), anemia secondary to renal disease, anemia due to chronic diseases/ inflammation, and a group with unidentifiable causes, i.e. "unexplained anemia". ${ }^{(16)}$

The hyper-inflammatory condition is a characteristic feature of anemia of inflammation (AI), chronic kidney disease (CKD) and inflammaging. This condition is marked by increased production of hepcidin in the liver, a direct negative impact on erythropoiesis, and increased iron retention in the reticulo-endothelial system (RES). Subsequently erythropoietin (EPO) production cannot adequately respond to the anemia, and the EPO response in erythropoiesis weakens. Another definitive marker in the pathogenesis of $\mathrm{AI}$ is increased phagocytosis of senescent red blood cells (eryptosis). Clonal abnormalities in the leukocytes increase the risk of developing cardiovascular complications and anemia. This association may be due to increased inflammation (Figure 2). ${ }^{(15)}$ Although the NHANES study results present complete critical data on the prevalence of various types of anemia in community-dwelling elderly, the criteria used to define the various causes have important limitations, such as the lack of a clinical background, lack of evaluation of peripheral blood smears, or evaluation of reticulocyte response to anemia, all of which are important information for the clinical evaluation of patients with anemia. Therefore, the NHANES categories do not include other causes that may underlie the anemias in the elderly, such as myelodysplasia, leukemia, and hemolysis, that may emerge upon a more comprehensive clinical and hematological examination. The prevalence of anemia in the elderly based on identification of the causes from the study results of France, ${ }^{(23)}$ Chicago ${ }^{(24)}$ and SHC/VAPAHCS ${ }^{(25)}$ are presented in Figure 3.

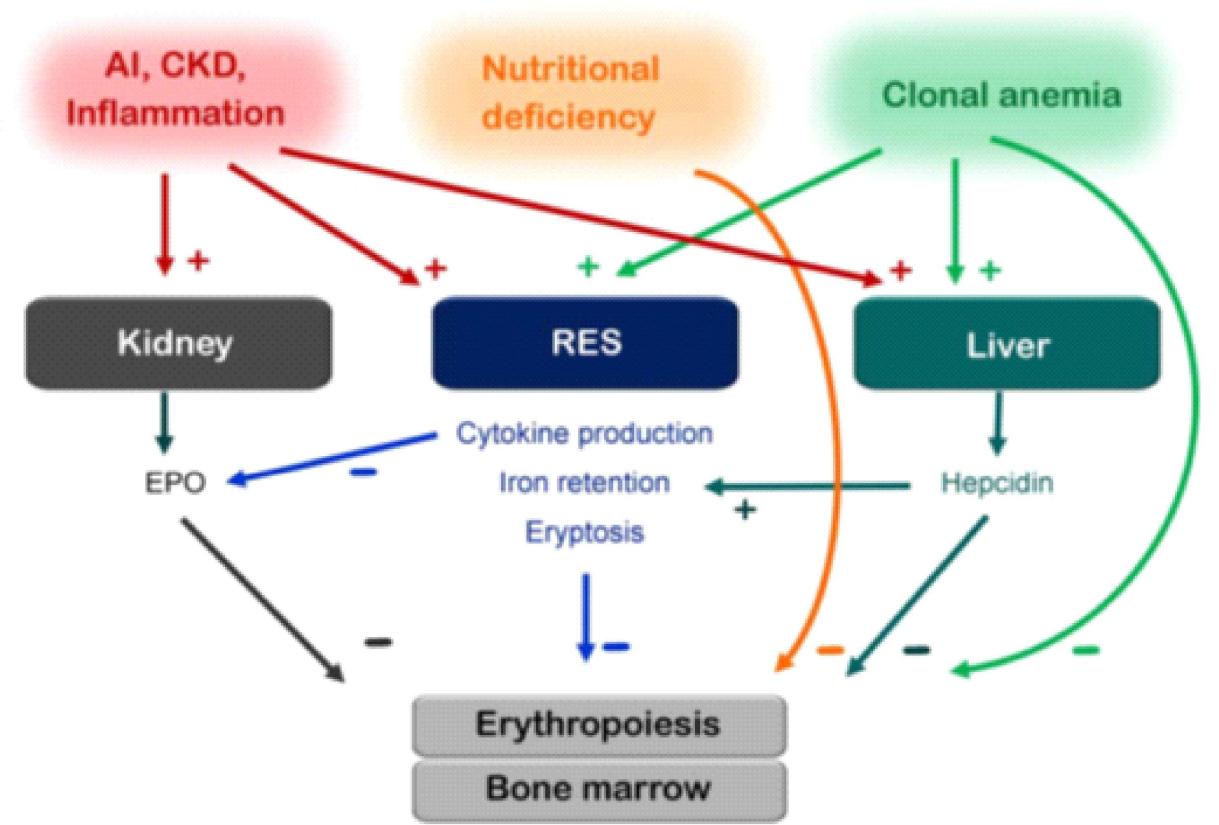

Figure 2. Possible etiologic mechanisms of anemia in the elderly ${ }^{(15)}$ 

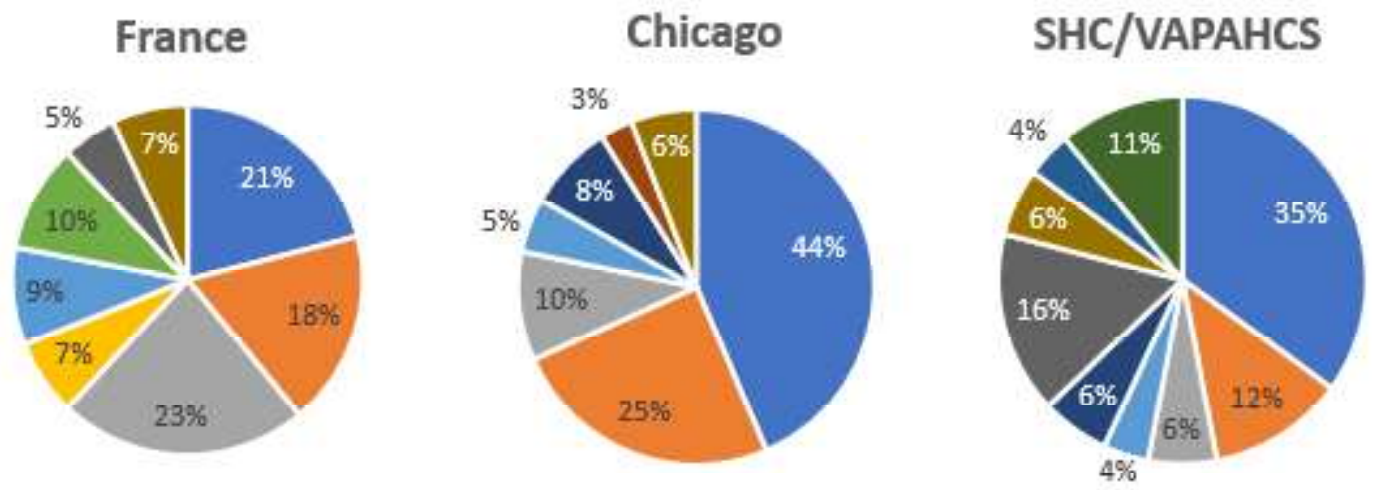

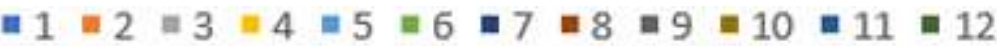

Figure 3. Prevalence of anemia in the elderly based on identification of the causes from the results of studies in France, ${ }^{(23)}$ Chicago ${ }^{(24)}$ and SHC/VAPAHCS. ${ }^{(25)}$ 1) UAE = unidentified anemia of elderly; 2) IDA= iron deficiency anemia; 3) AI = anemia of inflammation; 4) Liver \& endocrine disease 5) CKD = anemia secondary to renal disease; 6) Folate and/or B12 deficiency; 7) Hematologic malignancy; 8) Thalassemia; 9) Susp MDS= suspicious for myelodysplastic; 10) other; 11) Incomplete; 12) Therapy for Non-Hematologic Malignancy

Two publications of other cross-sectional studies have provided clarification on the distribution of the different causes of anemia in the elderly after a comprehensive hematological examination was done. ${ }^{(24,25)}$ These latter studies differ from NHANES in that the evaluation was performed on clinical hematological referral patients in academic centers. Artz and Thirman (24) carried out an evaluation on elderly patients with anemia, who were grouped by race, and the majority of whom were Africa-American women. The comprehensive hematological evaluation of patients was conducted in one academic hematology clinic. The study reported that unexplained anemia of the elderly (UAE) was the most frequently found category of anemia in the elderly, marked by an erythropoietin concentration that was low for the degree of anemia. Price et al. ${ }^{(25)}$ performed an evaluation of elderly patients with anemia, most of whom were Caucasians, who had been referred to veterans clinics or university/academic hematology clinics. Although comprehensive hematological evaluation was done on the elderly patients with anemia, unexplained anemia of the elderly (UAE) was still the largest category of anemia that was marked by erythropoietin concentrations that were low for the degree of anemia.
From the results of two other studies on anemia in the elderly that were carried out in hematological reference clinics using the criterion of eGFR of less than $30 \mathrm{~mL} / \mathrm{min} / 1.73 \mathrm{~m}^{2}$, only 3 $4 \%$ of the cases of anemia in the elderly was secondary to renal disease, which percentage was also lower than the estimates from the NHANES III study. Although the primary pathogenesis of anemia secondary to renal disease is abnormal erythropoietin production, the inflammatory process may have contributed to the development of anemia in these patients. ${ }^{(26)}$ The studies carried out by Artz and Thirman (24) and Price et al. ${ }^{(25)}$ also performed prospective and precise evaluation on anemia in the elderly to identify the cases misclassified as unidentified anemia of elderly (UAE), such as drug intoxications, alcohol abuse, myelodysplasia, and hematological malignancies. However, these investigators still obtained UAE frequencies of 30 and $40 \%$, respectively, in spite of the intensive hematological investigations, the results being identical to the previous estimates. The results of the study by Waalen et al. ${ }^{(27)}$ reported that elderly males with UAE had lower testosterone concentrations than the controls without anemia, such that this finding supports the supposition that hormonal deficiency may be one of the factors contributing to the development of UAE in males. Another possible 
cause of UAE is dysregulation of growth hormone/insulin-like growth factor-1 (IGF-1) in controlling erythropoietin secretion in the liver, because low IGF-1 concentrations are associated with anemia in elderly individuals. ${ }^{(28)}$

The studies conducted by Artz and Thirman ${ }^{(24)}$ and Price et al. ${ }^{(25)}$ found that 7.5 and $6 \%$, respectively, of cases of anemia in the elderly were definitely caused by hematological malignancies, with the majority of cases being identified as myelodysplasia syndrome (MDS). The referral clinics in these two studies may have made excessive overall estimates of the prevalence of MDS and acute myeloid leukemia in the population of elderly with anemia. In spite of this, MDS and hematological malignancies are also not infrequently found, and may only be detected through a comprehensive hematological evaluation in elderly patients with anemia.

\section{Impact of anemia on physical functions in the elderly}

Anemia as a multifactorial condition must be accepted as fact, and the increased comorbidities in the elderly makes it difficult to determine whether anemia is a marker of disease burden or an intermediate condition in the course of the disease, as a side effect. Anemia in the elderly is frequently overlooked, although the facts show that low hemoglobin concentration is an important marker of physiological decline.

Anemia may cause a decrease in physical functions, such as causing functional limitations and falls. ${ }^{(29-32)}$ Anemia in the elderly that is not manageable is associated with fatigue, falls, fractures, osteoporosis, increased risk of comorbidities, cardiovascular diseases, functional and mental limitations and death, as well as constituting an economic burden. Although suffering from chronic disease, an elderly person may have a fair degree of health and be able to perform activities of daily living, have a social life and manage finances. Health-related quality of life (HRQoL) may be a measure of health level and focused on the quality of life associated with the health status. ${ }^{(33,34)}$
From many epidemiological studies it may be demonstrated that anemia is associated with several relevant clinical conditions. A crosssectional study investigated the association between anemia and disability, physical performance, and muscle strength on 1156 community-dwelling individuals aged 65 years or older. After adjustment for age, gender, body mass index, Mini Mental State Examination (MSME) score, creatinine concentration, and various comorbid conditions, individuals with anemia suffered from disability (1.71 vs 1.04 ; $\mathrm{p}=0.002)$ and poorer performance ( 8.8 vs 9.6 ; $\mathrm{p}=0.003$ ) as compared with individuals without anemia. Individuals with anemia also had less strength in the knee extensor muscles (14.1 vs $15.2 \mathrm{~kg} ; \mathrm{p}=0.02)$ and lower handgrip strength ( 25.3 vs $27.1 \mathrm{~kg} ; \mathrm{p}=0.04)$ as compared with individuals without anemia. ${ }^{(35)}$

From the results of a study conducted on elderly patients between 65 and 90 years of age, a significant association was found between hemoglobin concentration and functional status, as assessed with the functional independence measure (FIM). ${ }^{(30)}$ In this study, the FIM score was lower (showing low functional ability) in elderly patients with mild anemia (hemoglobin concentration $<12 \mathrm{~g} / \mathrm{dL}$ ) as compared with elderly subjects with normal hemoglobin concentration (hemoglobin concentration $\geq 12 \mathrm{~g} / \mathrm{dL}$ ). Similarly, functional limitations as a result of anemia were also reported in patients with chronic renal failure. ${ }^{(35)}$ In one other study on elderly females an evaluation was made on the association of hemoglobin concentration and the resulting limitations of mobility, with summary performance score. The incidence of mobility limitations of was not constant in the group of females with normal hemoglobin concentration based on World Health Organization standards (12.0-16.0 g/dL). The group with hemoglobin concentration of $13 \mathrm{~g} / \mathrm{dL}$ had a significant association with decreased incidence rate of mobility limitations, as compared with the group of subjects with hemoglobin concentration of $12.0 \mathrm{~g} / \mathrm{dL}$. These results showed that slightly low or low normal hemoglobin 
concentrations had individual impacts on mobility functions. Therefore, the hemoglobin concentration of $12.0 \mathrm{~g} / \mathrm{dL}$ may be less appropriate to be used as definition of anemia in elderly females. ${ }^{(36)}$ It has also been reported that anemia may cause the elderly to become prone to falls, and that falls are the main cause of death and a source of morbidity in the elderly population. ${ }^{(36)}$ From the results of a community-based study that evaluated the association between the incidence of falls in subjects aged 65 years or older and with chronic health conditions, it can be shown that anemia has a significant association with incidence of falls, even after adjustment for demographic variables and consideration of the risk factors. The definitive mechanism as to how anemia may cause a person to fall is still incompletely understood, but it may be assumed that the association between weakness and vertigo causes a person to more easily fall. ${ }^{(37)}$ It can also be predicted that the decrease in physical function in an individual as a result of anemia may impact on the quality of life of that individual.

\section{Impact of anemia on quality of life}

Anemia is a major complication of chronic kidney disease, and significantly contributes to patient mortality and morbidity, including impaired physical and cognitive function, and reduced quality of life. ${ }^{(38)}$ The concept of quality of life comprises satisfaction and well-being, including subjective and multi-dimensional characteristics. Quality of life may be understood as quality of life in general or as health-related quality of life (HRQoL). Formerly this term comprised something more extensive, namely the feeling of well-being and happiness, irrespective of problems of disease or dysfunction. When quality of life is linked to the context of health and disease, it is usually known as health-related quality of life (HRQoL), to differentiate it from other aspects of quality of life. The World Health Organization (WHO) ${ }^{(32)}$ defines quality of life as "an individual's perception of his/her life situation, that is understood in the context of culture, value system, and in connection with goals, expectations and prevailing standards in a given social environment". From this perspective, HRQoL comprises the areas of physical health, psychological status, degree of individual independence, interpersonal relations, beliefs in the context of special factors or natural environment, and social support that is accepted or felt.

Self-assessed health status is also a powerful predictor of morbidity and mortality as compared with many other objective health measures. In this connection, many gerontologists are of the opinion that successful elderly are those who feel happy and are content with the past and present, and also enjoy positive social relations and contacts. This concept also refers to the dimension of subjective well-being, to the ability for adaptation, to adequate acceptance and appreciation of the environment, such that he or she may have a better perception of health and well-being. This is related to the explanation how the elderly run their lives, cognitive evaluation, emotional reaction, their adaptation to life, and independence in performing activities of daily living. ${ }^{(39)}$ This is the reason why it is essential to introduce self-assessment, satisfaction with daily functioning and feeling of independence, and the wish for participation, as factors to be taken into account, and constituting an important component of the overall structure of the quality of life standards in the elderly. ${ }^{(39)}$

In health-related quality of life (HRQoL), the approach is multidimensional, comprising the physical, mental, and social aspects that are actually associated with symptoms, incapacity, and limitations that arise because of disease. ${ }^{(32,33)}$ From the results of a literature study carried out by Schnittker and Bacak ${ }^{(40)}$ it was found that the mortality risk was higher in individuals with normal or poor self-rated health than in those with good self-rated health. Although health is an important part of the overall quality of life, there are also other important factors, such as occupation, housing, school and environment. Additionally, the cultural aspects, values, and spirituality are also important parts of the quality of life, and add to the complexity of its assessment. 


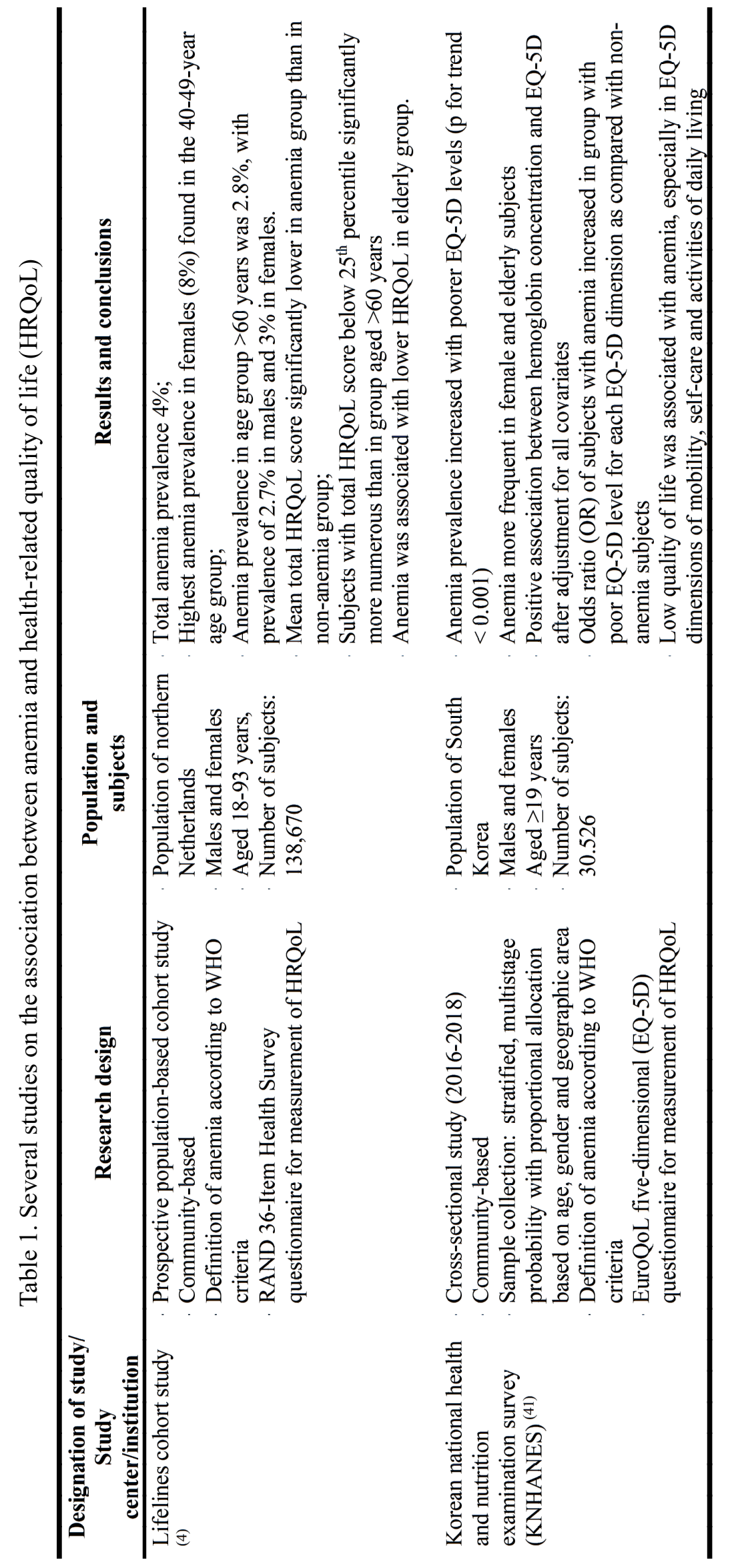




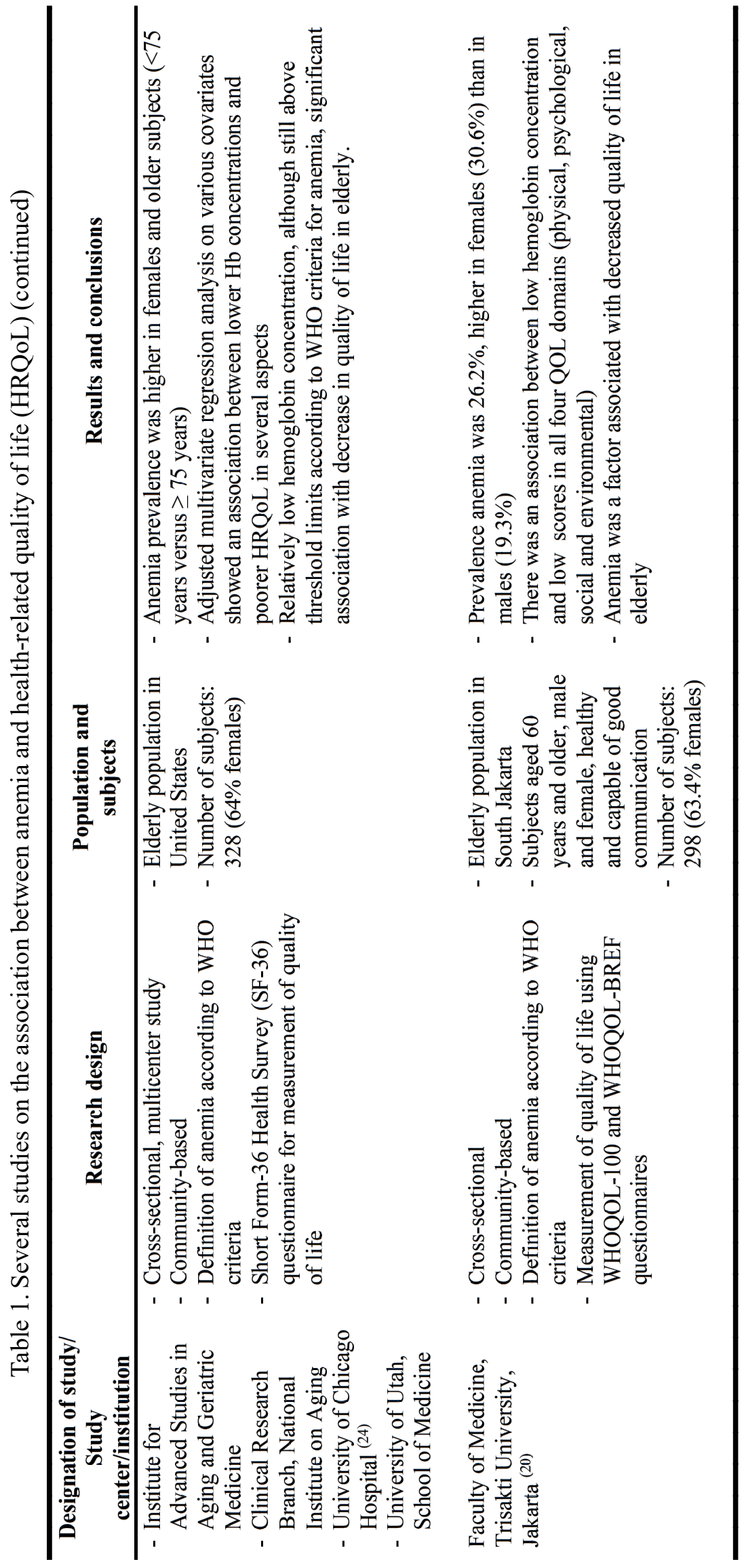


The impact of anemia on health-related quality of life (HRQoL) has been studied in patients from various differing populations, and most of the studies state that there is an association between HRQoL and anemia in elderly individuals, particularly in the subscale of physical health. This shows that younger individuals may compensate better for the impact of anemia on physical health, and limit the impact of anemia on their quality of life (HRQoL). In older individuals, this compensatory mechanism is more limited than in younger ones. The ability to perform physical activity is known to be important in maintaining the quality of life of the elderly.

The Lifelines population-based cohort study (4) investigated this problem with data from a survey using the RAND-36 questionnaire for assessing health-related quality of life ${ }^{(4)}$ and hemoglobin concentration of around 138,670 subjects aged 18-93 years. The definition of anemia used was according to the World Health Organization (WHO) and subsequently a subclassification was used for subjects aged 60 years and older. From the results of this study an anemia incidence was found in $5510(4 \%)$ of 138,670 subjects and $516(2.8 \%)$ of 18,667 individuals aged more than 60 years. A lower health-related quality of life was mainly found in the subscale of physical function. The elderly had a lower mean HRQoL in the subscales of physical function, social function, physical role function, emotional role function, vitality, body pain and health in general. A limitation of this study was that the RAND-36 questionnaire is for generic evaluation of health status and not specifically for anemia patients, such that the results may be have been affected by subject bias.

In South Korea, data from the Korean National Health and Nutrition Examination Survey (41) using the EQ-5D questionnaire ${ }^{(44)}$ showed that the overall incidence of anemia in individuals aged 10 years and older was around $8.2 \%$ in the years 2005-2015, in which there was a decrease in incidence rate from $8.5 \%$ in 2005 to $6.4 \%$ in 2015 . From this study it was found that anemia was more frequently found in females and elderly subjects, and those individuals with poor nutritional status, low education, and low income. This KNHANES study also reported the presence of an association between anemia and HRQoL, especially with regard to mobility, self-care and activities of daily living. In healthy persons, the food consumed is converted into energy with the help of oxygen, whereas a low hemoglobin concentration in patients with anemia produces a reduced oxygen supply. ${ }^{(45)}$ This mechanism may explain why subjects with anemia experience limitations in physical performance. Similarly, reduced muscle strength and density are associated with anemia, thus resulting in reduced mobility, self-care ability and activities of daily living. ${ }^{(46,47)}$ Anemia is associated with chronic diseases such as malignancies, chronic kidney disease (CKD), and inflammatory bowel disease, that are commonly followed by iron deficiency, inflammation and organ complications. ${ }^{(48,49)}$ It has also been reported that anemia affects quality of life in the elderly and in frail patients, especially in connection with physical performance. ${ }^{(50,51)} \mathrm{A}$ previous study found that low hemoglobin level was an important factor influencing muscle strength in patients with hematological malignancies. ${ }^{(52)}$ In Brazilia, anemia is associated with difficulties or limitations in mobility in females with chronic diseases. ${ }^{(50)}$

Another cross-sectional study was also done in South Jakarta, involving 289 study subjects in the elderly group, consisting of 109 (36.6\%) males and 189 (63.4\%) females, using the WHO criteria for anemia status and the WHOQOL-BREF questionnaire for the measurement of the subjects' quality of life. ${ }^{(20)}$ The results of this study showed that the prevalence of anemia in the elderly reached $26.2 \%$, with a higher prevalence in the group of females as compared with males. The quality of life in the physical, psychological, social and environmental domains had significant differences with decreases in hemoglobin concentration, while the quality of life in the physical and mental domains also decreased significantly with increasing age. 


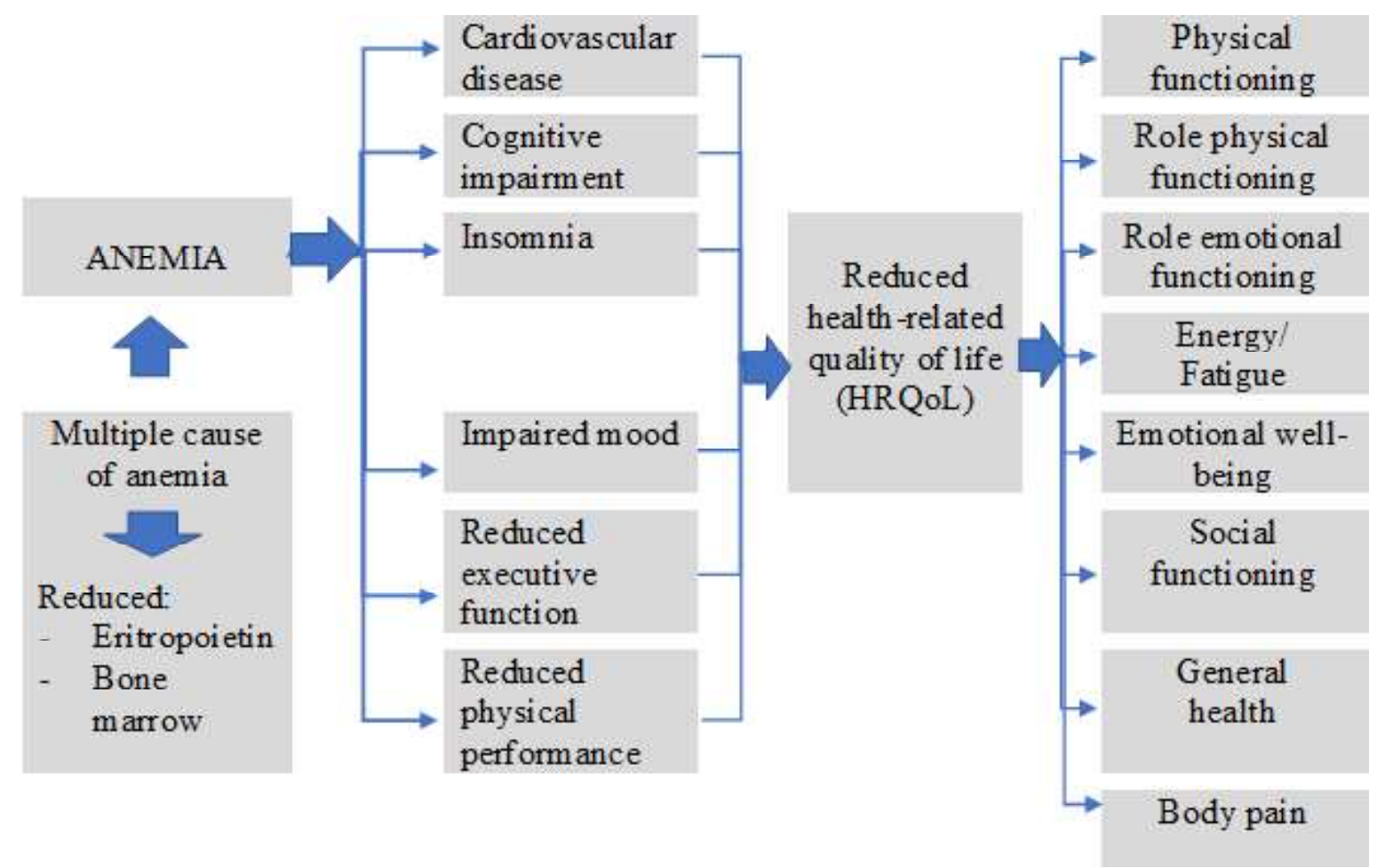

Figure 4. Relationship of anemia with reduced health-related quality of life and its various aspects

Although there is as yet no consensus on the subclassification of anemia, the available data show that anemia from chronic inflammation is associated with survival capacity and reduced health-related quality of life (HRQoL). Various multivariate analytical models conclude that anemia is an independent risk factor for reduced health-related quality of life in the elderly. It was also found that the HRQoL data were significantly poorer in females with hemoglobin concentrations between $12.0-13.0 \mathrm{~g} / \mathrm{dL}$ (categorized as anemia in males, but not in females), particularly in the elderly. These study results also constitute a challenge for the definition of anemia in elderly females (aged $>60$ years), leading to the proposal of a more optimal definition of anemia, in the perspective of health-related quality of life, namely a hemoglobin concentration of less than $13.0 \mathrm{~g} / \mathrm{dL}(8.0 \mathrm{mmol} / \mathrm{L})$, as is also defined in males. ${ }^{(4)}$

\section{Management of anemia and HRQoL in the elderly}

Although the incidence of anemia in the elderly is relatively high, this does not mean that anemia is in the aging process. The underlying causes of anemia may be encountered in nearly $80 \%$ of patients. ${ }^{(5,53)}$ Therefore, it is important to identify the causes and start appropriate treatment to prevent more severe anemia, slow down the course of the disease, and improve the patient's prognosis. The benefits of early diagnosis and therapy in anemia have been demonstrated in patients with heart failure or chronic renal failure, in which an improvement could be observed in patients with side effects associated with the disease. ${ }^{(5)}$ As an example, the results of clinical studies provide evidence that correction of anemia will raise hemoglobin levels, reduce the proportion of patients requiring transfusions and improve patients' QoL. ${ }^{(54)}$ Patients with heart failure not only experience improvement in cardiac function, but also reduced needs for diuretics and hospitalization. Furthermore, it is said that treatments to reduce fatigue and other symptoms associated with anemia have positive effects on quality of life. This shows that identification and treatment of anemia in the elderly will decrease the incidence of cardiovascular complications and associated mortality. ${ }^{(5,15,30)}$ 
Therefore, early diagnosis of anemia is important to prevent this condition from deteriorating, to retard progress of the disease, and improve the patient's condition. The physicians or health personnel should also pay attention to HRQoL in patients with anemia, especially in the elderly. The available data also show that overall prognosis becomes better with management and improvement of anemia in patients with chronic disease, such as congestive heart disease, and this has a significant positive effect on the quality of life. ${ }^{(5,55)}$

Optimal treatment should be adjusted for age, by paying attention to the potential adverse effects and also its impact on quality of life. Frail elderly patients requiring weekly injections will face problems because of difficulties in transportation, thus affecting their quality of life. If possible, the main goal is to treat and eliminate the underlying diseases and the etiology of anemia. In the majority of patients with iron deficiency, administration of oral iron appears to be beneficial. ${ }^{(56)}$ Furthermore, in recent years new oral iron formulations such as Ferric Maltol (57) and Sucrosomial Iron (58) showing high effectiveness and fewer adverse effects, have obtained approval, such as to reduce the need for intravenous administration of iron. Occasionally oral iron supplementation in the elderly is less effective because of the reduced uptake in the gastrointestinal tract, problems of compliance and/or inflammatory states that decrease utilization of iron. ${ }^{(59,60)}$ Currently a number of iron formulations are available that can be administered intravenously, such as iron sucrose, ferric gluconate and ferumoxytol. In recent years, newer and safer formulations have been approved, mainly ferric carboxymaltose and iron isomaltoside that are much prescribed by physicians. Preparations of ferric carboxymaltose and also other iron isomaltosides, although rarely, may cause severe hypophosphatemia followed by osteomalacia and bone fractures, especially if administered in high doses to patients with severe iron deficiency and relatively normal renal function. ${ }^{(61)}$ Therefore, intravenous iron supplementation may be recommended if oral iron administration is not tolerated by the patient, in patients who refuse oral administration of iron substitutes, and in cases of bleeding or less effective iron absorption in the digestive tract.

\section{CONCLUSIONS}

The high prevalence of anemia throughout the world and the higher incidence rate in Asian women as compared to men, should have our common attention. Although in the last decades the mortality rate has been successfully reduced and the life span has increased, the community does not only want a long life, but also an optimal health-related quality of life (HRQoL). Because of the high incidence of anemia in the elderly population, understanding the relationship between anemia and HRQoL in the elderly is an important objective.

Early diagnosis of anemia is important to prevent this condition from deteriorating, to retard the progress of the disease, and to improve health and quality of life of the patient. A comprehensive evaluation on the cases of anemia in elderly individuals is important to be performed to determine the pathological condition of the cause of anemia, the presence or absence of comorbidities or other diseases that may emerge simultaneously in an already old individual. Prior to determining the plan of treatment, the primary diagnosis and comorbidities, especially treatable disorders, should preferably be identified.

\section{CONTRIBUTORS}

All authors participated in writing the manuscript and preparing the figures. All authors read and approved the final draft.

\section{REFERENCES}

1. World Health Organization, Regional Office for South-East Asia. Prevention of iron deficiency anaemia in adolescents. WHO Regional Office for South-East Asia;2011. 
2. Lopez A, Cacoub P, Macdougall IC, PeyrinBiroulet L. Iron deficiency anaemia. Lancet 2016; 387:907-16. doi: 10.1016/S0140-6736(15)60865-0.

3. World Health Organization. The global prevalence of anaemia 2011. Geneva: World Health Organization;2015.

4. Wouters HJCM, van der Klauw MM, de Witte T, et al. Association of anemia with health-related population-based cohort study. Haematologica 2019;104:468-76. DOI: 10.3324/haematol.2018. 195552.

5. Goodnough LT, Schrier SL. Evaluation and management of anemia in the elderly. Am J Hematol 2014;89:88-96. doi: 10.1002/ajh.23598 2014;89(1):88-96.

6. World Health Organization. WHAGlobal Nutrition Targets 2025: anaemia policy brief. Geneva: World Health Organization;2014.

7. United Nations, Department of Economic and Social Affairs PD. United Nations: World population ageing 2015. New York: United Nations;2015.

8. UNFPA Indonesia. Indonesia on the threshold of population ageing. Monograph Series No.1. Jakarta: UNFPA Indonesia;2014.

9. Zilinski J, Zillmann R, Becker I, Benzing T, Schulz RJ, Roehrig G. Prevalence of anemia among elderly inpatients and its association with multidimensional loss of function. Ann Hematol 2014;93:1645-54. doi: 10.1007/s00277-014-2110-4.

10. Pang WW, Schrier SL. Anemia in the elderly. Curr Opin Hematol 2012; 19:133-40. doi: 10.1097/MOH. 0b013e3283522471.

11. Migone de Amicis M, Poggiali E, Motta I, et al. Anemia in elderly hospitalized patients: prevalence and clinical impact. Intern Emerg Med 2015;10:581-6. doi: 10.1007/s11739-015-1197-5.

12. Tettamanti M, Lucca U, Gandini F, et al. Prevalence, incidence and types of mild anemia in the elderly: The "Health and Anemia" population-based study. Haematologica 2010;95: 849-56. doi: 10.3324/haematol.2010.023101.

13. Vanasse GJ, Berliner N. Anemia in elderly patients: an emerging problem for the 21 st century. Hematology Am Soc Hematol Educ Program 2010: 271-5. DOI: 10.1182/asheducation-2010.1.271.

14. World Health Organization. Haemoglobin concentrations for the diagnosis of anaemia and assessment of severity. Geneva: World Health Organization;2011.

15. Stauder R, Valent P, Theurl I. Anemia at older age: etiologies, clinical implications, and management. Blood 2018;131:505-14. https://doi.org/10.1182/ blood-2017-07-746446.
16. Seitz AE, Eberhardt, Lukacs SLAnemia prevalence and trends in adults aged 65 and older: US National Health and Nutrition Examination Survey: 2001-2004 to 2013-2016. JAm Geriatr Soc 2018; 66:2431-2. https://doi.org/10.1111/jgs.15530.

17. Rohrig G, Gütgemann I, Leischker A, Kolb G. Anemia in the aged - a geriatric syndrome?: Second position paper on anemia in the aged by the working group anemia of the German Geriatric Society. Z Gerontol Geriatr 2018;51:919-21. doi: 10.1007/s00391-018-1457-x.

18. Song P, Li L, Man Q, Wang C, Meng L, Zhang J. Case-control study of anaemia among middleaged and elderly women in three rural areas of China. BMJ Open 2014;4:8. doi: 10.1136/bmjopen2013-004751.

19. Callera F, Callera AF, da Silva AM, Rosa ES. Prevalence of anemia in a sample of elderly southeastern Brazilians. Rev Bras Hematol Hemoter 2015;37:43-7. http://dx.doi.org/10.1016/ j.bjhh.2014.06.005.

20. Meiyanti, Kalumpiu JV, Mulia JI. Anemia decreases quality of life of the elderly in Jakarta. Univ Med 2009;28:152-60. DOI: 10.18051/ UnivMed.2009.v28.152-160.

21. Styszynski A, Mossakowska M, Chudek J, et al. Prevalence of anemia in relation to socioeconomic factors in elderly Polish population: the results of PolSenior study. J Physiol Pharmacol 2018;69:75-81.DOI: 10.26402/jpp.2018.1.08.

22. Randi ML, Bertozzi I, Santarossa C, et al. Prevalence and causes of anemia in hospitalized patients: impact on diseases outcome. J Clin Med 2020; 9: 950. doi: 10.3390/jcm9040950.

23. Andrès E, Mecili M. Anaemia in elderly patients. Blood Transfus 2011;9:108-9. doi: 10.2450/2010. 0028-10.

24. Artz AS, Thirman MJ. Unexplained anemia predominates despite an intensive evaluation in a racially diverse cohort of older adults from a referral anemia clinic. J Gerontol A Biol Sci Med Sci 2011;66A:925-32. doi: 10.1093/gerona/glr090.

25. Price EA, Mehra R, Holmes TH, Schrier SL. Anemia in older persons: etiology and evaluation. Blood Cells Mol Dis 2011;46:159-65. doi: 10.1016/ j.bcmd.2010.11.004.

26. Babitt JL, Lin HY. Mechanisms of anemia in CKD. J Am Soc Nephrol 2012; 23: 1631-4. doi: 10.1681/ ASN.2011111078.

27. Waalen J, von Löhneysen K, Lee P, Xu X, Friedman JS. Erythropoietin, GDF15, IL6, hepcidin and testosterone levels in a large cohort of elderly individuals with anaemia of known and unknown cause. Eur J Haematol 2011;87:107-16. doi: 10.1111/j.1600-0609.2011.01631.x. 
28. De Vita F, Maggio M, Lauretani F, et al. Insulinlike growth factor-1 and anemia in older subjects: the InCHIANTI study. Endocr Pract 2015;21: 1211-8. doi:10.4158/EP14100.OR.

29. Abrahamsen JF, Bjorke-Monsen A, Landi F, Haugland C, Nilsen RM, Hylen Ranhoff A. Readmission and mortality one year after acute hospitalization in older patients with explained and unexplained anemia - a prospective observational cohort study. BMC Geriatrics 2016; 109. DOI : 10.1186/s12877-016-0284-4.

30. Fukushima T, Nakano J, Ishii S, et al. Influence of hemoglobin level on muscle and physical functions, activities of daily living, and quality of life in patients with hematological malignancies. Integr Cancer Ther 2019;18: 1-10. https://doi.org/ 10.1177/1534735419842196.

31. Zakai NA, French B, Arnold AM, et al. Hemoglobin decline, function, and mortality in the elderly: the cardiovascular health study. Am J Hematol 2013;88:5-9. doi: 10.1002/ajh.23336.

32. de Melo RLP, da Silva Junior EG, Souto RQ, Leão IS, do Carmo Eulalio M. Psychometric properties of the complete version of the World Health Organization Quality of Life Assessment (WHOQOL-OLD): reduced response scale. Psicol Reflex Crít 2018;31:4. DOI: 10.1186/s41155-0180084-1.

33. Karimi M, Brazier J. Health, health-related quality of life, and quality of life: what is the difference? Pharmacoeconomics 2016;34:645-9. doi: 10.1007/ s40273-016-0389-9.

34. Hirani V, Naganathan V, Blyth F, et al. Low hemoglobin concentrations are associated with sarcopenia, physical performance, and disability in older Australian men in cross-sectional and longitudinal analysis: the Concord Health and Ageing in Men Project. J Gerontol ABiol Sci Med Sci 2016;71:1667-75. doi:10.1093/gerona/glw055.

35. Hazin MAA. Anemia in chronic kidney disease. Rev Assoc Med Bras 2020; 66 Suppl 1:S:55-S8. http://dx.doi.org/10.1590/1806-9282.66.S1.55.

36. Ruan Y, Guo Y, Kowal P, et al. Association between anemia and frailty in 13,175 community-dwelling adults aged 50 years and older in China. BMC Geriatrics 2019 19:327. https://doi.org/10.1186/ s12877-019-1342-5.

37. Paliwal Y, Slattum PW, Ratliff SM. Chronic health conditions as a risk factor for falls among the community-dwelling US older adults: a zeroinflated regression modeling approach. Bio Med Res Int 2017, Article ID 5146378, 9 pages. https:/ /doi.org/10.1155/2017/5146378.

38. Drüeke TB. Lessons from clinical trials with erythropoiesis-stimulating agents (ESAs). Renal
Replace Ther 2018; 4:46. https://doi.org/10.1186/ s41100-018-0187-2.

39. Rondón Garcia LM, Ramírez Navarrro JM. The impact of quality of life on the health of older people from a multidimensional perspective.. J Aging Res 2018; Article ID 4086294, 7 pages. https://doi.org/10.1155/2018/4086294.

40. Schnittker J, Bacak V. The increasing predictive validity of self-rated health. PLoS ONE 2014;9: e84933. doi:10.1371/journal.pone.0084933. I

41. Kim Y, Do HK, Cho K, Kim Y, Park Y. Anemia and health-related quality of life in South Korea/ : data from the Korean national health and nutrition examination survey 2008 - 2016. BMC Public Health 2019;19:735. doi: 10.1186/s12889-019-6930y.

42. Geisel T, Martin J, Schulze B, et al. An etiologic profile of anemia in 405 geriatric patients. Anemia 2014; Article ID 932486, 7 pages. http://dx.doi.org/ 10.1155/2014/932486.

43. Varela FRA, Ciconelli RM, Campolina AG, de Soarez PC. Quality of life evaluation of frail elderly in Campinas, São Paulo. Rev Assoc Med Bras 2015;61:423-30. http://dx.doi.org/10.1590/18069282.61.05.423.

44. Hong J. Relative importance of the EQ-5D five dimensions among patients with chronic diseases in South Korea - a comparison with the general population preference weights. Health Qua Life Outcomes 2018; 16:159. https://doi.org/10.1186/ s12955-018-0987-7.

45. Bang SM, Lee JO, Kim YJ, et al. Anemia and activities of daily living in the Korean urban elderly population: results from the Korean Longitudinal Study on Health and Aging (KLoSHA). Ann Hematol 2013;92:59-65. DOI: 10.1007/s00277-012-1563-6.

46. Le CHH. The prevalence of anemia and moderatesevere anemia in the US population (NHANES 2003-2012). PLoS One 2016;11:1-14. http:// dx.doi.org/10.1371/journal.pone.0166635

47. Vulser H, Wiernik E, Hoertel N, et al. Association between depression and anemia in otherwise healthy adults. Acta Psychiatr Scand 2016;134: 150-60. https://doi.org/10.1111/acps.12595.

48. De Franceschi L, Iolascon A, Taher A, Cappellini MD. Clinical management of iron deficiency anemia in adults: systemic review on advances in diagnosis and treatment. Eur J Intern Med 2017;42:16-23. DOI: 10.1016/j.ejim.2017.04.018.

49. Kanuri G, Sawhney R, Varghese J, Britto M, Shet A. Iron deficiency anemia coexists with cancer related anemia and adversely impacts quality of life. PLoS ONE 2016;11:e0163817. doi:10.1371/ journal.pone.0163817. 
50. Corona LP, Andrade FCD, de Oliveira Duarte YA, Lebrao ML. The association of hemoglobin concentration with disabilily and decreased morbidity among older Brazilians. J Nutr Health Aging 2013;18:336-41. DOI: 10.1007/s12603-0130389-9.

51. Wasada I, Eguchi H, Kurita M, Kudo S, Shishida T, Mishima Y, et al. Anemia affects the quality of life of japanese cancer patients. Tokai J Exp Clin Med 2013;38:7-11.

52. Nakano J, Ishii S, Fukushima T, Natsuzako A, Sakamoto J, Okita M. Factors affecting muscle strength in cancer patients receiving chemotherapy. J Nov Physiother Rehabil 2017;1:56-66. DOI: 10.29328/journal.jnpr.1001008.

53. Bianchi VE. Anemia in the elderly Population. J Hematol 2014;3:95-106. doi: http://dx.doi.org/ 10.14740/jh182w.

54. Chen L, Jiang H, Gao W, et al. Combination with intravenous iron supplementation or doubling erythropoietin dose for patients with chemotherapy induced anaemia inadequately responsive to initial erythropoietin treatment alone: study protocol for a randomised controlled trial. BMJ Open 2016;6:e012231.doi:10.1136/ bmjopen-2016-012231.

55. Alexandrakis MG, Tsirakis G. Anemia in heart failure patients. ISRN Hematology 2012, Article ID 246915, 9 pages. doi:10.5402/2012/246915.
56. Tay HS, Soiza RL. Systematic review and metaanalysis: what is the evidence for oral iron supplementation in treating anaemia in elderly people? Drugs Aging 2015;32:149-58. doi: 10.1007/s40266-015-0241-5.

57. Gasche C,Ahmad T, Tulassay Z, et al. Ferric maltol is effective in correcting iron deficiency anemia in patients with inflammatory bowel disease: Results from a phase-3 clinical trial program. Inflamm Bowel Dis 2015;21:579-88. doi: 10.1097/ MIB.0000000000000314.

58. Gómez-Ramírez S, Brilli E, Tarantino G, Muñoz M. Sucrosomial ${ }^{\circledR}$ iron: a new generation iron for improving oral supplementation. Pharmaceuticals 2018;11:1-23. doi: 10.3390/ph11040097.

59. Silay K, Akinci S, Yalcin A, et al. The status of iron absorption in older patients with iron deficiency anemia. Eur Rev Med Pharmacol Sci 2015;19:3142-5.

60. Franceschi C, Campisi J. Chronic inflammation (inflammaging) and its potential contribution to age-associated diseases. J Gerontol - Ser A Biol Sci Med Sci. 2014;69:S4-9. doi: 10.1093/gerona/ glu057.

61. Zoller H, Schaefer B, Glodny B. Iron-induced hypophosphatemia: An emerging complication. Curr Opin Nephrol Hypertens 2017;26:266-75. doi: 10.1097/MNH.0000000000000329. 